\title{
BOARDING SCHOOL: A SIMPLE APPROACH TO REDUCE SOIL TRANSMITTED HELMINTH INFECTIONS IN ORANG ASLI CHILDREN OF SUNGAI SIPUT, PERAK, 2017
}

\author{
Adilah Aminuddin ${ }^{1,2}$, Hassan Basri Jahubar Sathik ${ }^{1,3}$, Hani Syifaa Mohd Hashim ${ }^{1}$, Abdul Rashid Khan ${ }^{1}$ and \\ Siti Fatimah Kader Maideen ${ }^{1}$ \\ ${ }^{1}$ Department of Public Health, RCSI \& UCD Malaysia Campus, 4, Jalan Sepoy Lines, Georgetown, \\ Pulau Pinang, Malaysia \\ ${ }^{2}$ Klinik Kesihatan Bayan Lepas, Jalan Dato Ismail Hashim Bayan Lepas, 11900, Pulau Pinang, Malaysia \\ ${ }^{3}$ University of Cyberjaya, Persiaran Bestari, Cyber 11, 63000, Cyberjaya, Malaysia
}

Corresponding author: Adilah Aminuddin

Email: adilahaminuddin@yahoo.com

\begin{abstract}
Soil transmitted helminth (STH) infection is a major public health concern among the indigenous children of Malaysia. Precarious living conditions at home including unavailability of water, drinking of contaminated water, poor sanitation and livestock presence, are known risk factors for the infection. In order to provide better living conditions, these children are enrolled in boarding schools. This study was conducted to determine whether boarding schools is a solution in reducing soil transmitted helminth infection among Orang Asli children in Sg Siput, Perak, Malaysia. An analytical cross-sectional study was conducted among 204 schoolchildren aged 7-17 years from three boarding schools in Sungai Siput, Perak from January to March 2017. Stool samples were collected and examined using direct smear and Kato-Katz technique. Information on sociodemographic and environmental conditions were collected using a modified Demographic Health Survey (DHS) questionnaire. Data analysis was done using IBM SPSS Statistics Processor 20.0.Out of a total of 204 children, only 48\% ( $n=97)$ were infected with at least one type of STH species which showed a reduced prevalence as compared to previous studies conducted among home dwelling schoolchildren with overall prevalence of 78-97\%. Majority of the children had monoparasitism (31\%; $n=63)$ with moderate intensity by $T$ trichuira $(n=51,25 \%)$. Univariate analysis shows that unavailability of water at home has a statistically significant association with STH infection among boarding school children $(O R=0.73 ; 95 \% \mathrm{Cl}=0.56-0.95 \mathrm{p}=0.021)$. Multivariate analysis proves children who had unavailability of water at home has 2.1 times more likelihood of getting an STH infection $(\mathrm{OR}=2.08$; $95 \% \mathrm{Cl}=$ 1.07-4.07; $p=0.032$ ). This study demonstrates a reduced STH prevalence among Orang Asli boarding school children as better living condition there limits the spread of STH infection among them.
\end{abstract}

Keywords: Soil transmitted helminth, Helminthiasis, Environmental factors, Boarding school, Children, Orang Asli, Prevalence, Malaysia

\section{INTRODUCTION}

Soil transmitted helminth infection are a group of parasitic intestinal parasites known to infect millions of people worldwide. It is one of the neglected tropical disease, mostly affecting children giving rise to detrimental consequences to their physical, nutrition and cognitive development.

According to World Health Organization (WHO), $24 \%$ of the worldwide population are infected with Soil Transmitted Helminth(STH) and these population are concentrated over Sub-Saharan Africa, the Americas, China and East Asia ${ }^{1}$. Among these, 270 million preschool-age children and more than 600 million school-aged children live in areas endemic of this infectious disease and are at high risk of infection ${ }^{1}$. In India, reported prevalence for at least a single STH infection ranges from $13 \%$ to as high as $66 \%^{2}$. In Vietnam, it is extrapolated that in $2003,44 \%$ of its population is affected by the most prevalent type of STH infection, A. lumbricoides ${ }^{3}$. Similarly from the 500 million people residing in Sub Saharan
Africa, STH infection accounts for up to $85 \%$ of all neglected tropical diseases ${ }^{4}$.

As its name suggests, soil transmitted helminth has a reservoir in the soil which can easily transmit to human either directly via ingestion of soil or penetration of skin ${ }^{5}$. There are three main types of STH which are Trichuris trichiura, Ascaris lumbricoides and hookworms (Necator americanus and Ancylostoma duodenale).

In Malaysia, Orang Asli are most susceptible to this insidious parasitic infection. Orang Asli is a term which simply translates to 'original people' or the aboriginal. They consist of three large ethnic subgroups known as Semang (Negrito), Senoi and Proto-Malay, which are further divided into 18 smaller subgroups. The majority $(86 \%)$ of Orang Asli lives in the rural area and due to this geopraphical disadvantage, their exposure to soil transmitted helminth (STH) infection increases ${ }^{6}$.

A recent study shows that infection of STH among the Orang Asli tribes in Peninsular Malaysia was as high as $81 \%$ with a higher prevalence in children 
less than 15 years old ${ }^{7}$. Long term infection by these parasites especially in children, may cause significant morbidity such as malnutrition and delayed cognitive development ${ }^{8}$. According to a study done in Malaysia, lack of toilets in residential areas as well as inaccessibility of clean water for consumption contributes to high prevalence of STH among schoolchildren ${ }^{9}$. Another study also suggested that individuals who have high intensity of STH infection not only has a higher risk of infection with different subtypes but is also seen as high risk source of environmental contamination ${ }^{10}$. Besides that, human to animal interaction is also associated with STH infection. According to a study among school children in Guizhou and Sichuan, China, possession of livestock explained $2 \%$ difference in infection rate between case and control groups ${ }^{11}$.

The disparities in health and economics of the Orang Asli with the rest of Malaysian citizen are obvious. $76.9 \%$ of the Orang Asli live below the poverty line ${ }^{12}$. Average life expectancy also differs by 20 solid years while infant mortality rate among the Orang Asli is as high as 51.7 per 1000 live birth ${ }^{13}$.

In order to close this gap, the Government of Malaysia has built boarding schools as an initiative to improve educational opportunities for the Orang Asli children as well as to improve their health status. Better environmental and hygienic conditions in boarding schools should warrant better living prospect for the children as compared to the exposure they get at home. As suggested by previous studies, cleaner environmental conditions may lead to a reduced prevalence of STH infection among the boarding school dwellers.

Therefore, the objective of this study is (i) to investigate the prevalence and intensity of STH infection among Orang Asli children attending boarding school (ii) to determine the socio demographic characteristics of the children attending boarding schools in Perak and its association with STH infection (iv) to identify the association between water source, availability of proper sanitation facilities and livestock presence with STH infection.

\section{METHODS}

\section{Study population}

This is an analytical cross-sectional study, done in the state of Perak, Northwest of Peninsular Malaysia, home for 53,299 Orang $\mathrm{Asli}^{14}$. In the state of Perak and Kedah itself, there are 28 Orang Asli schools with a total of 4978 students ranging from kindergarten to 12 years of age ${ }^{14}$. The Orang Asli of Perak holds second place for being the most impoverished after Orang Asli in Pahang with a total of 2828 people earning below the poverty line ${ }^{14}$. Sungai Siput is located in the city of Kuala Kangsar and covers about $61 \%$ of the total area of the city.

In Sungai Siput, there are three major boarding schools in which data collection was done which are SMK Bawong, SK Kampung Kenang and SMAR Nurul Hidayah. The study sample were selected based on purposive sampling method with proportionate allocation. The minimum sample size required for this study was calculated using Open Epi Sample Size Calculator. Based on the study by Ngui et al, the most significant proportion of STH infection among Orang Asli (majorly aged less than 12 years old) with regards to lack of safe water supply is $86.8 \%$ as compared to those with safe water supply at $62.4 \%{ }^{15}$.

\section{Sampling method}

Based on the prevalence above, with the power of $90 \%$ and $95 \%$ of confidence interval, the total sample size calculated is 204 children including $33 \%$ non-response rate as seen in a study done in Pos Sederut, Pahang and a $18 \%$ non-eligibility rate which is estimated from a study done in Satak, Raub, Pahang ${ }^{16,17}$.

This study included three boarding schools with a total of 589 students. From the 186 students from SK Kampung Kenang, 150 from SMAR Nurul Hidayah and 253 from SMK Bawong, based on their proportionate allocation, 64 number of children were selected from SK Kampung Kenang, 52 from SMAR Nurul Hidayah and 88 from SMK Bawong as shown in Figure 1.

\section{Data collection}

For stool sample collection, each participant was given a sample container with a spatula attached, in which on the external surface of each container is marked with their participant's registration number. A demonstration on proper stool sampling method was done and the participants were given 3 days to return the samples. Polystyrene boxes containing ice packs were placed at the multipurpose hall of each school, handled by research assistants assigned there, available throughout the day from $7 \mathrm{am}$ to $10 \mathrm{pm}$. Students were asked to return the collection bottles immediately after passing of stool.

For the purpose of transport, the unpreserved specimens were properly sealed and cold packs were used in order to keep the specimens cold for the 3- hour drive to the Department of Parasitology, University Kebangsaan Malaysia, for examination by trained laboratory personnel using direct microscopy and Kato-Katz technique. For every positive specimen under direct microscopy, another examination using Kato Katz technique followed to examine the 
Total of 589 Orang Asli school children enrolled in three boarding schools; Sekolah Kebangsaan Kampung Kenang $(n=186)$, SMAR Nurul Hidayah $(n=150)$ AND Sekolah Menengah Kebangsaan Bawong $(n=253)$ Total $(\mathrm{n}=\underline{\mathbf{5 8 9}})$

From proportionate allocation of students to achieve $n=204$;

$\underline{64}$ students were needed from SK Kpg Kenang, $\underline{\mathbf{5 2}}$ from SMAR Nurul Hidayah \& $\underline{88}$ from SMK Bawong

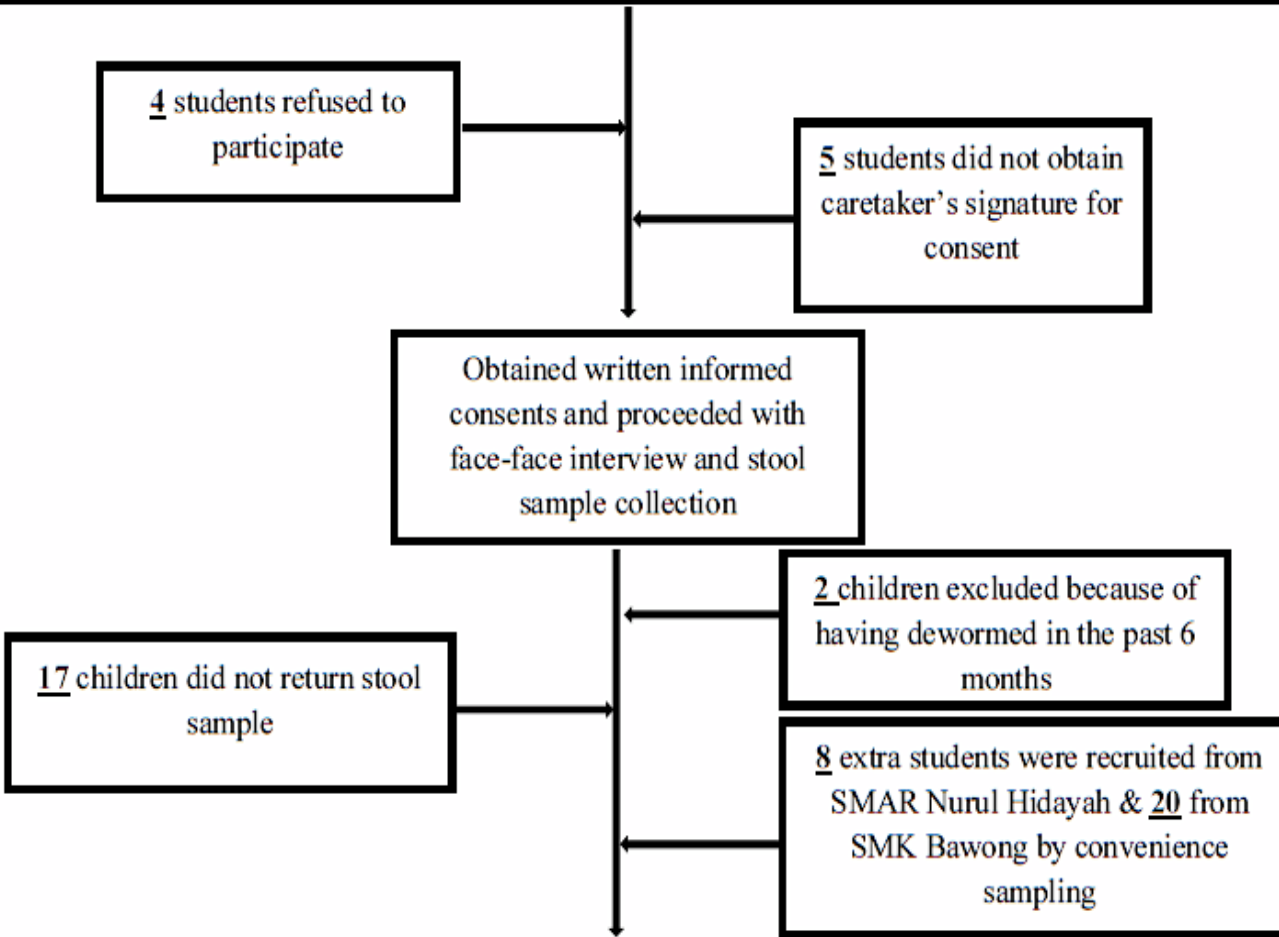

204 children had complete data record including signed informed consent, completion of face-face interview and delivered stool sample.

Figure 1: Flowchart of participant selection and outcome

stool sample for egg count which estimated the intensity of STH infection recorded as eggs per gram of stool. During analysis, the intensity of infection was then categorised into light, moderate or heavy infection based on the criteria proposed by World Health Organisation ${ }^{18}$.

In terms of the questionnaire, The Demographic Health Survey (DHS) Questionnaire which is a validated questionnaire was utilised ${ }^{19}$. For the purpose of this study, some parts of this questionnaire were modified in which certain questions that was irrelevant to the research question were eliminated. The entire document was then translated into Malay using back-back translation method and later a pilot study was conducted among 39 schoolchildren of SK (Asli) Bukit Cheding, Banting, Kuala Langat, Selangor, a state west coast of Malaysia. From this pilot study, one item from the original DHS 
questionnaire was removed in order to achieve a Cronbach Alpha of 0.6. as suggested by The British Psychological Steering Committee on Test Standards $(1977)^{20}$.

\section{Data analysis}

Data was entered and analysed using IBM SPSS Statistics Processor 20.0. Descriptive analysis is presented in percentages in order to exhibit clearly the prevalence of STH infection based on their sociodemographic and risk factors. In univariate analysis, Pearson chi-squared $\left(x^{2}\right)$ and Fischer exact test were used to determine the statistically significant risk factors to the dependent variable. $P$ value of $<0.05$ is used, in which odds ratio (OR) and $95 \%$ confidence interval $(\mathrm{Cl})$ are documented in the respective tables. In order to determine the predictors of STH infection, all variables that showed association with $\mathrm{p} \leq 0.25$ in the univariate analysis were retained for modelling by multivariate logistic regression as suggested by Bendel and Afifi ${ }^{21}$. A p- value of $<0.05$ in the final model indicated a significant variable.

\section{RESULTS}

\section{Descriptive analysis}

Overall, almost half of the students, $(48 \%, n=97)$ of the participants were tested positive to be infected by at least one type of STH species. The most predominant infection is T. trichiura (45\%), followed by A. lumbricoides (14\%) and hookworm infection only infected $2.0 \%$ of the study sample.

With regards to the intensity of infection, all three types of STH infections exhibits light to heavy infections. The worm burden of T. trichiura was the most with a quarter of the children showing infection of moderate intensity $(n=51$, $25 \%$ ) followed by light infection at $18 \%$ and heavy at only $2 \%$ as presented in Table 1.

Table 1: Prevalence and intensity of infection among Orang Asli boarding school children in Sg Siput, Perak

\begin{tabular}{|c|c|c|c|c|c|c|}
\hline \multirow[t]{3}{*}{ Intensity } & \multicolumn{6}{|c|}{ Type of infection } \\
\hline & \multicolumn{2}{|c|}{ Trichuriasis } & \multicolumn{2}{|c|}{ Ascariasis } & \multicolumn{2}{|c|}{ Hookworm } \\
\hline & $\mathrm{n}$ & $\%$ & $\mathrm{n}$ & $\%$ & $\mathrm{n}$ & $\%$ \\
\hline Light & 36 & 17.6 & 16 & 7.8 & 3 & 1.5 \\
\hline Moderate & 51 & 25.0 & 12 & 5.9 & 1 & 0.5 \\
\hline Heavy & 4 & 2.0 & - & - & - & - \\
\hline Overall & 91 & 44.6 & 28 & 13.7 & 4 & 2.0 \\
\hline
\end{tabular}

Furthermore, based on this population, single infection $(n=63,31 \%)$ were the most common, followed by double infections $(n=33,16 \%)$ and lastly, with only one person having triple infection $(0.5 \%)$. The most predominant single infection is T. trichiura with 61 (30\%) students having infected with T. trichiura only while for dual infection, the combination of T. trichiura and $\mathrm{A}$. lumbricoides are the most eminent $(\mathrm{n}=30$, $15 \%)$ among other dual infections as presented in Table 2.

Two hundred and four Orang Asli boarding school children with a mean age of 13.9 (standard deviation, $S D=1.73$ ) participated in this study.

The following table (Table 3) depicts the sociodemographic characteristics of these children.
Analytic analysis

With regards to sociodemographic and environmental risk factors, only two variables are significantly associated with STH by univariate analysis that is "mothers with primary

education" $(\mathrm{OR}=1.43 ; 95 \% \mathrm{Cl}=0.63-3.24 \mathrm{p}=0.044)$ and "unavailability of primary water source" $(\mathrm{OR}=0.73 ; 95 \% \mathrm{Cl}=0.56-0.95 \mathrm{p}=0.021)$. The results are represented in Table 4.

Based on multivariate logistic regression analysis, children who had unavailability of water at home has 2.1 times more likelihood of getting an STH infection among the Orang Asli boarding school children $(\mathrm{OR}=2.08 ; 95 \% \mathrm{Cl}=1.07-4.07 ; \mathrm{p}=0.032)$. 
Table 2: Monoparasitism and polyparasitism among boarding schoolchildren in Sg Siput, Perak

\begin{tabular}{lcc}
\hline Type of infection & $\mathbf{n}$ & $\%$ \\
Monoparastism & 63 & 30.9 \\
T. trichiura & 61 & 29.9 \\
Hookworms & 2 & 1.0 \\
Polyparasitism & 33 & \\
Two species (total) & 30 & 16.2 \\
T. trichiura \& A. lumbricoides & 3 & 14.7 \\
A. lumbricoides \& Hookworms & 1 & 1.5 \\
Three species & & 0.5 \\
\hline
\end{tabular}

Table 3: General characteristics of Orang Asli boarding school children in Sg Siput, Perak

\begin{tabular}{lcc}
\hline Sociodemographic factors & $\mathrm{n}$ & $\%$ \\
\hline Age $^{\mathrm{a}}$ & & \\
$7-9$ years old & 5 & 2.5 \\
$10-12$ years old & 13 & 15.2 \\
$13-15$ years old & 29 & 68.1 \\
16-17 years old & & 14.2 \\
Gender & 76 & \\
Male & 128 & 37.3 \\
Female & & 62.7 \\
Children education level & 36 & \\
Primary School & 168 & 17.6 \\
Secondary School & & 82.4 \\
Place of residence & 183 & \\
Within Perak & 9 & 95.3 \\
Outside Perak & & 4.7 \\
Mother's education level & & \\
Informal education & 43 & 25.4 \\
Primary education & 96 & 56.8 \\
Secondary education & 30 & 17.8 \\
Father's education level & & \\
Informal education & & 26.2 \\
Primary school & 39 & 49.7 \\
Secondary school & 74 & 24.2 \\
\hline
\end{tabular}

a categorised according to level of schooling set by Ministry of Education, Malaysia 
Malaysian Journal of Public Health Medicine 2020, Vol. 20 (3): 195-204

Table 4: Univariate analysis of sociodemographic and environmental factors with STH prevalence

\begin{tabular}{|c|c|c|c|c|c|c|c|c|c|}
\hline \multirow[t]{2}{*}{ Sociodemographic factors } & \multicolumn{2}{|c|}{$\begin{array}{c}\text { STH } \\
\text { presence }\end{array}$} & \multicolumn{2}{|c|}{$\begin{array}{c}\text { STH } \\
\text { absence }\end{array}$} & \multicolumn{2}{|c|}{ Total } & \multirow[t]{2}{*}{$\begin{array}{l}\text { Odds } \\
\text { ratio }\end{array}$} & \multirow[t]{2}{*}{$95 \% \mathrm{Cl}$} & \multirow[t]{2}{*}{ p-value } \\
\hline & $\mathrm{n}$ & $\%$ & $\mathrm{n}$ & $\%$ & $\mathrm{n}$ & $\%$ & & & \\
\hline \multicolumn{10}{|l|}{ Education level } \\
\hline Primary & 16 & 16.5 & 20 & 18.7 & 36 & 17.6 & 1.07 & $0.77-1.49$ & $0.681^{b}$ \\
\hline Secondary & 81 & 83.5 & 87 & 81.3 & 168 & 82.4 & & & \\
\hline \multicolumn{10}{|l|}{ Gender } \\
\hline Male & 36 & 37.1 & 40 & 37.4 & 76 & 37.3 & 1.01 & $0.77-1.31$ & $0.968^{b}$ \\
\hline Female & 61 & 62.9 & 67 & 62.6 & 128 & 62.7 & & & \\
\hline \multicolumn{10}{|l|}{ Hometown } \\
\hline Within Perak & 87 & 95.6 & 96 & 95.0 & 183 & 95.3 & 0.94 & $0.52-1.72$ & $1.000^{c}$ \\
\hline Outside of Perak & 4 & 4.4 & 5 & 5.0 & 9 & 4.7 & & & \\
\hline \multicolumn{10}{|l|}{ Mother's education level } \\
\hline Informal education & 27 & 32.9 & 15 & 17.2 & 42 & 24.9 & 0.56 & $0.21-1.44$ & $0.044^{b}$ \\
\hline Primary education & 40 & 48.8 & 57 & 65.5 & 97 & 57.4 & 1.43 & $0.63-3.24$ & \\
\hline Secondary education & 15 & 18.3 & 15 & 17.2 & 30 & 17.8 & $1^{d}$ & & \\
\hline \multicolumn{10}{|l|}{$\begin{array}{l}\text { Father's education level } \\
\text { (category) }\end{array}$} \\
\hline Informal education & 21 & 28.8 & 17 & 22.4 & 38 & 25.5 & 0.65 & $0.26-1.62$ & $0.630^{\mathrm{b}}$ \\
\hline Primary education & 36 & 49.3 & 39 & 51.3 & 75 & 50.3 & 0.87 & $0.39-1.93$ & \\
\hline Secondary education & 16 & 21.9 & 20 & 26.3 & 36 & 24.2 & $1^{\mathrm{d}}$ & & \\
\hline \multicolumn{10}{|l|}{$\begin{array}{l}\text { Primary source of } \\
\text { drinking water }\end{array}$} \\
\hline Treated $\dagger$ & 90 & 95.7 & 99 & 92.5 & 189 & 94.0 & 0.79 & $0.52-1.20$ & $0.336^{\mathrm{b}}$ \\
\hline Untreatedł & 4 & 4.3 & 8 & 7.5 & 12 & 6.0 & & & \\
\hline \multicolumn{10}{|l|}{$\begin{array}{l}\text { Unavailability of primary } \\
\text { water source* }\end{array}$} \\
\hline Yes & 54 & 65.1 & 48 & 48.0 & 102 & 55.7 & 0.73 & $0.56-0.95$ & $0.021^{\mathrm{b}}$ \\
\hline No & 29 & 34.9 & 52 & 52.0 & 81 & 44.3 & & & \\
\hline \multicolumn{10}{|l|}{$\begin{array}{l}\text { Ensuring safe drinking } \\
\text { water at home }\end{array}$} \\
\hline Yes & 83 & 90.2 & 88 & 90.7 & 171 & 90.5 & 1.03 & $0.63-1.67$ & $0.906^{\mathrm{b}}$ \\
\hline No & 9 & 9.8 & 9 & 9.3 & 18 & 9.5 & & & \\
\hline \multicolumn{10}{|l|}{$\begin{array}{l}\text { Steps to ensure safe } \\
\text { water at home } \\
\text { Boils water }\end{array}$} \\
\hline Yes & 83 & 88.3 & 84 & 84.8 & 167 & 86.5 & 0.87 & $0.61-1.25$ & $0.483^{b}$ \\
\hline No & 11 & 11.7 & 15 & 15.2 & 26 & 13.5 & & & \\
\hline \multicolumn{10}{|l|}{ Strain with cloth } \\
\hline Yes & 16 & 17.0 & 12 & 12.1 & 28 & 14.5 & 0.81 & $0.52-1.28$ & $0.334^{b}$ \\
\hline No & 78 & 83.0 & 87 & 87.9 & 165 & 85.5 & & & \\
\hline \multicolumn{10}{|l|}{ Water filter } \\
\hline Yes & 3 & 3.2 & 3 & 3.0 & 6 & 3.1 & 0.98 & $0.43-2.19$ & $1.000^{c}$ \\
\hline No & 91 & 96.8 & 96 & 97.0 & 187 & 96.9 & & & \\
\hline \multicolumn{10}{|l|}{ Stand and settle } \\
\hline Yes & 3 & 3.2 & 6 & 6.1 & 9 & 4.7 & 1.32 & $0.813-2.14$ & $0.499 c$ \\
\hline No & 91 & 96.8 & 93 & 93.9 & 184 & 95.3 & & & \\
\hline \multicolumn{10}{|l|}{ Type of facility at home } \\
\hline Proper toilet & 82 & 84.5 & 92 & 86.0 & 174 & 85.3 & 1.06 & $0.72-1.55$ & $0.771^{\mathrm{b}}$ \\
\hline $\begin{array}{l}\quad \text { No facility } \\
\text { Presence of livestock at } \\
\text { home }\end{array}$ & 15 & 15.5 & 15 & 14.0 & 30 & 14.7 & & & \\
\hline Yes & 54 & 55.7 & 69 & 64.5 & 123 & 60.3 & 1.20 & $0.90-1.58$ & $0.199^{b}$ \\
\hline No & 43 & 44.3 & 38 & 35.5 & 81 & 39.7 & & & \\
\hline
\end{tabular}

†Treated: piped water, tanker truck and bottled water, fUntreated water: tube well/bore hole, dug well, water from spring, rain water and surface water, b Pearson chi-squared test $\left(\mathbf{x}^{2}\right)$

c Fischer exact test, ${ }^{d}$ Logistic regression 


\section{DISCUSSION}

\section{Magnitude of the study}

This study sets out to assess the prevalence and intensity of STH infection among Orang Asli boarding school children and to see its association with environmental risk factors such as source of drinking water, improper sanitation and presence of livestock around the household.

This study has shown that $48 \%$ of the study population were found to be positive of at least one type of STH infection with T. trichiura being the most predominant species of infection at $46 \%$. The overall infection rate found in this study is rather small as compared to other previous studies done among school aged children in various parts of Malaysia such as Terengganu, Pahang and Perak, reporting overall prevalence ranging from $78 \%-97 \%$ as depicted in the graph below 22-26.

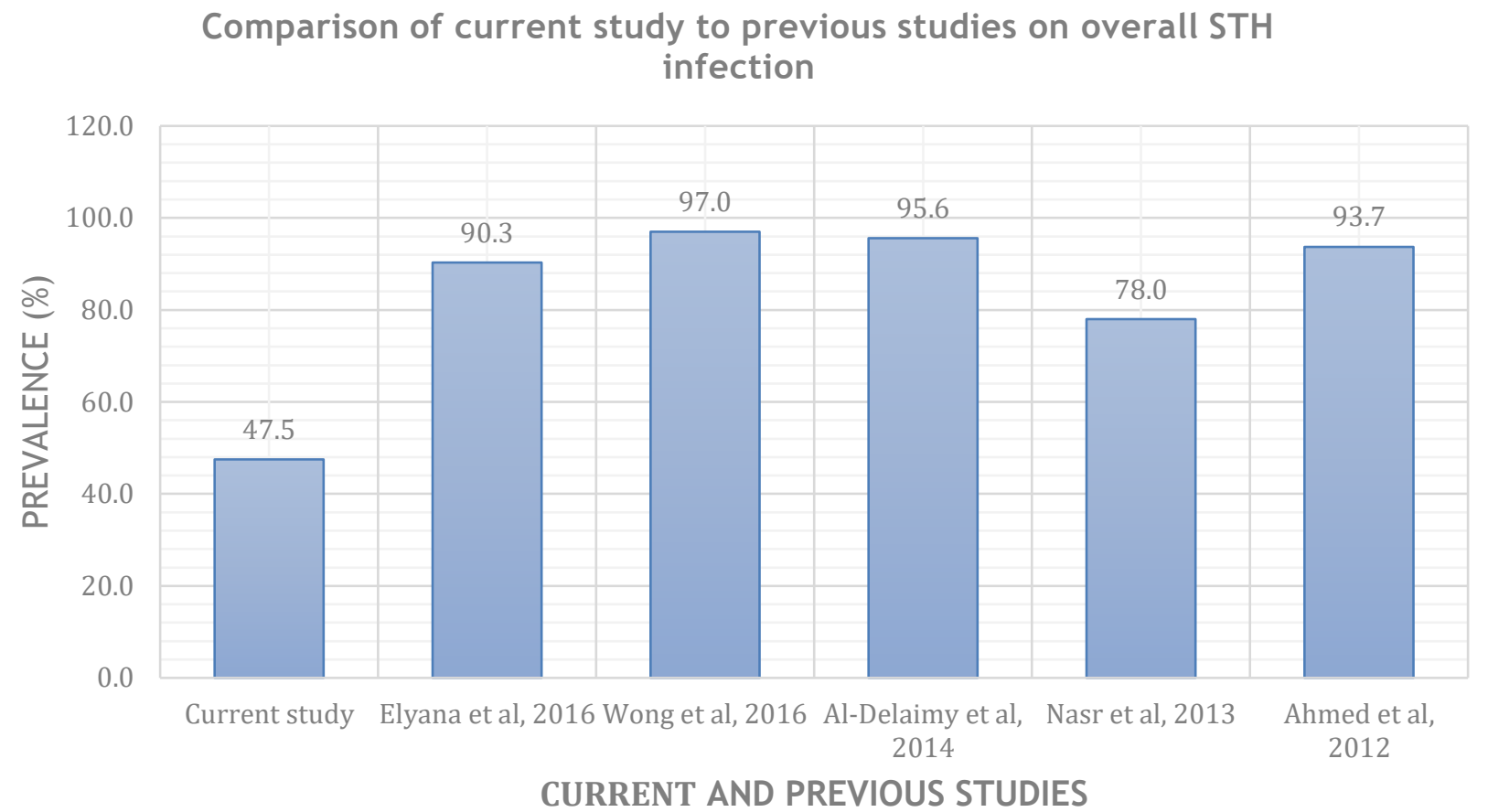

Figure 2: Comparison of current study to previous studies on overall STH infection among school aged children.

\section{Cause-effect relationship}

The reason behind this decrease in prevalence is most likely because these children reside in boarding schools. The better infrastructure and accommodation in boarding schools may have caused a shift in epidemiology which decreases exposure to risk factors of STH leading to a lower infection rate. Furthermore, adapting to better

lifestyle practices which are taught by nonaboriginal teachers may have led to the decrease in transmission of helminth among the school dwellers. One previous study done among school boarders in the Peruvian rainforest supports this and similarly, the study associated good environmental and hygiene standards in school and low exposure to risk factors at home, for the reduction in prevalence as compared to pupils living in towns and the rest of San Lorenzo community ${ }^{27}$. Another similar study done among Tarahumara tribe's boarding school in Northern Mexico also concluded that appropriate community-based strategies to improve household conditions may reduce the growth and transmission of parasites ${ }^{28}$.
However, these findings challenge a recent study among Inland Jungle Villages (IJV) Negritos and those who had undergone resettlements under the Resettlement Plan Scheme (RPS) in which there was no significant difference found in the prevalence of STH infection among these two groups ${ }^{29}$. This study concluded that the hygiene practices of the aborigines especially open defecation with poor hand hygiene were main culprits to continuous and growing transmission of STH infection and poverty as well as overcrowding as seen in RPS vicinity created a suitable breeding ground for certain parasitic species. Although aboriginals were provided with better environmental commodities, they preferred to openly defecate rather than to use the toilets provided. However, with boarding school and children, it may be different as the governing bodies of the school has to adhere to specific standards of infrastructure and maintenance such as providing adequate toilets, wash basins, limitation of number of students and with teachers instilling proper hygiene practices among the children, the chain of transmission of helminth might have been broken, leading to 
decreased prevalence of STH infection as seen in this study. Similarly, a case control study done in East Java proved that schoolchildren provided with combined latrine-education intervention resulted in a lesser prevalence of STH infection as compared to the control subgroup ${ }^{30}$.

Prevalence of double infection by T. trichiura and A. lumbricoides is also lower (14.7\%) in the current study as compared to other studies with prevalence of $18.9 \%$ and $20 \%$ respectively ${ }^{31,32}$. Nevertheless, to some extent, the Orang Asli children under this study might still not have a perfect hygiene practice as majorly are seen to have moderate intensity infection of $T$. trichuira when a light intensity would have been anticipated.

This study has also concluded that even though these children are enrolled in boarding schools, unavailability of water at their respective homes is a significant predictor for STH infection. This may be because these children do return to their homes in a fortnightly basis (over a weekend) thus re-exposing them to their native environment. Water regardless of source, becomes a necessity in order to reduce the prevalence of STH infection. This may be due to the importance of clean, functioning water which allows the children to practice hygienic habits such as hand hygiene, anal cleansing and cleaning of toilets which, according to previous studies, are all protective factors for intestinal parasitic infection ${ }^{33}$.

By the same token, in terms of sociodemographic characteristics, children having mothers who at least have primary education showed a higher prevalence of STH infection as compared to those with informal and secondary education. This finding is surprising as it is contrary to previous literatures which concluded that informal education is associated with a higher rate of intestinal parasitic infection ${ }^{34}$. However, if these mothers do actually attend primary school but do not complete their education, due to the known high drop-out rates among the Orang Asli (enrolment of $45 \%$ into primary and only $11 \%$ continued to lower secondary), then probably a vague and incomplete primary education does associates with a higher infection rate ${ }^{35}$.

\section{Limitations}

Other environmental risk factors investigated which are significant predictors in previous studies were not able to be re-proven in this study. This may be due to the limitation of the study itself in which questionnaires were answered by the children themselves. This may have led to recall bias as children under 18 years of age are ideally represented by a guardian/ parent in order to verify the information obtained. Nevertheless, as mentioned, the piloted questionnaires were made simple enough for answering by schoolchildren aided with pictures. Convenience sampling may have also contributed to biases as this study did not consider whether these children came from a rural village or resettlement vicinity which may affect the pool and intensity of STH studied among them prior to commencement of the study. In order to eliminate this bias, the children should ideally be given intervention to provide a controlled baseline of STH infection.

Besides that, this study relies on only two methods for analysis of the stool samples which are by direct smear and Kato- Katz technique. Direct smear which was used for its affordability and simplicity, became the main method of diagnosing helminth infection before proceeding with the Kato -Katz in order to determine the burden of infection in the study population. The traditional direct smear, although justifiable as efficient in detecting up to $93 \%$ of cases in previous studies, may cause a misdiagnosis as parasites in stools with high content of fat and debris may be missed $^{36-38}$. Ideally, newer methods of analysis such as FLOTAC, Formol- Ether Sedimentation or Centrifugal Flotation is preferable or all samples should be examined using Kato-Katz technique in order to get a higher yield of parasites however will incur a higher cost.

\section{CONCLUSION}

Overall, this study found that there is a lower prevalence of STH infection among Orang Asli boarding school children in Sungai Siput, Perak as compared to previous studies among homebound Orang Asli children with unavailability of primary water source and mother's education level associated with higher infection rates. In the population under our study, we can conclude that boarding schools may be helpful in reducing the burden of STH infection among Orang Asli children. However, a nationwide study involving Orang Asli boarding school children needs to be done in order to prove this representation in order to provide better health for the Orang Asli of Malaysia.

\section{ACKNOWLEDGEMENTS}

We wish to express our sincere gratitude to our families, staff of RCSI \& UCD Malaysia Campus, staff of The Department of Parasitology, Faculty of Medicine University Kebangsaan Malaysia, the respective headmasters and teachers of the boarding schools, respective Tok Batin, parents and all the schoolchildren as well as everyone else involved in this study, without whom this research would have been impossible.

\section{REFERENCES}

1. WHO. 2016. Soil Transmitted Helminth Infections Fact Sheet. Available: http://www.who.int/ (Accessed Nov 18 2016). 
2. Kattula D, Sarkar R, Ajjampur SSR, et al. Prevalence \& Risk Factors for Soil Transmitted Helminth Infection among School Children in South India. The Indian Journal of Medical Research, 2014; 139(1): 76-82.

2. Van Der Hoek W, De N, Konradsen F, et al. Current Status of Soil-Transmitted Helminths in Vietnam. The Southeast Asian Journal of Tropical Medicine and Public Health 2003; 34, 1-11.

4. Hotez PJ \& Kamath A. Neglected Tropical Diseases in Sub-Saharan Africa: Review of Their Prevalence, Distribution, and Disease Burden. PLoS Neglected Tropical Diseases 2009; 3(8): e412

5. Bethony J, Brooker S, Albonico M, et al. Soil-transmitted Helminth Infections: Ascariasis, Trichuriasis, and Hookworm. Lancet 2006 367(9521):1521-32

6. Norfariza Hanim K. 2008. Department of Statistics, Malaysia. Orang Asli in Peninsular Malaysia, Population and Housing Census of Malaysia 2000. Monograph Series No.3 ed. Putrajaya: Department of Statistics

7. Anuar TS, Salleh FM \& Moktar N. SoilTransmitted Helminth Infections and Associated Risk Factors in Three Orang Asli tribes in Peninsular Malaysia. Sci Rep 2014 4; 4101.

8. Brooker S, Clements ACA \& Bundy DAP. Global Epidemiology, Ecology And Control Of Soil-Transmitted Helminth Infections. Adv Parasitol 2006 62:221-61.

9. Al-Delaimy A, Hesham M, Lim Y, et al. Developing And Evaluating Health Education Learning Package (HELP) to Control Soil-Transmitted Helminth Infections Among Orang Asli Children in Malaysia. Parasites and Vectors 2014; 7:416

10. Hotez PJ, Bundy DA, Beegle $K$, et al. Helminth infections: Soil-Transmitted Helminth Infections And Schistosomiasis. In:Disease Control Priorities in Developing Countries. 2nd edition. Washington (DC): The International Bank for Reconstruction and Development, The World Bank; 2006. Chapter 24

11. Wang $X$, Zhang $L$, Luo $R$, et al. Soiltransmitted Helminth Infections and Correlated Risk Factors in Preschool and School-aged Children in Rural Southwest China. PLoS One 2012; 7(9), e45939.
12. Masron T, Masami F \& Ismail N. Orang Asli in Peninsular Malaysia: Population, Spatial Distribution and Socio-Economic Condition. Journal of Ritsumeikan Social Sciences and Humanities 2013;6:75-115

13. Rusaslina I. 2013. Left Behind: The Orang Asli under the New Economic Policy, Singapore, NUS Press \& SIRD \& ISEAS Publishing.

14. JAKOA 2014. Bilangan Kampung dan Penduduk Orang Asli Mengikut Negeri, 2014. In: Jabatan Kemajuan Orang Asli. www.data.gov.my/data/en_US/dataset/ kampung-dan-penduduk-orang-aslimengikut-negeri-2014 (assessed May 2017)

15. Ngul R, Ishak S, Chuen CS, et al. Prevalence and Risk Factors of Intestinal Parasitism in Rural and Remote West Malaysia. PLoS Neglected Tropical Diseases, 2011; 1; 5(3):e974.

16. Noor Azian M, San Y, Gan C, et al. Prevalence of Intestinal Protozoa in an Aborigine Community in Pahang, Malaysia. Tropical Biomedicine, 2007;24(1):55-62

17. Ahmed A, Al-Mekhlafi HM, Al-Adhroey AH, et al. The Nutritional Impacts of SoilTransmitted Helminths Infections Among Orang Asli Schoolchildren in Rural Malaysia. Parasites \& vectors 2012 1;5(1):119.

18. Montresor A, Crompton DW, Hall A, et al. Guidelines for the Evaluation of SoilTransmitted Helminthiasis and Schistosomiasis at Community Level. Geneva: World Health Organization, 1998; 1 -49.

19. DHS 2016. Demographic and Health Surveys; http://dhsprogram.com. (Accessed Nov 25 2016)

20. Loewenthal KM. An Introduction to Psychological Tests And Scales, Psychology Press.

21. Bendel RB \& Afifi AA. Comparison of Stopping Rules in Forward "Stepwise" Regression. Journal of the American Statistical Association, 1977; 72:46-53.

22. Elyana FN, Al-Mekhlafi HM, Ithoi I, et al. A Tale Of Two Communities: Intestinal Polyparasitism Among Orang Asli and Malay Communities in rural Terengganu, Malaysia. Parasite Vectors 2016; 9:398. 
23. Wong WK, Foo PC, Roze MNM, PIM CD, et al. Helminthic Infection and Nutritional Studies among Orang Asli Children in Sekolah Kebangsaan Pos Legap, Perak. Canadian Journal of Infectious Diseases and Medical Microbiology, 2016.

24. Al-Delaimy AK, Al-Mekhlafi HM, Nasr NA, et al. Epidemiology Of Intestinal Polyparasitism Among Orang Asli School Children in Rural Malaysia. PLoS Negl Trop Dis 2014 Aug 21;8(8):e3074

25. Nasr NA, Al-Mekhlafi HM, Ahmed A, et al. Towards an Effective Control Programme of Soil-Transmitted Helminth Infections among Orang Asli in Rural Malaysia. Part 1: Prevalence and associated key factors. Parasites \& Vectors 2013; 6,27.

26. Ahmed A, Al-Mekhlafi H, Azam M, et al. Soil-Transmitted Helminthiasis: A Critical But Neglected Factor Influencing School Participation of Aboriginal children in rural Malaysia. Parasitology 2012; 139(6):802-8.

27. Kroeger A, Schulz S, Witte B, et al. Helminthiasis and Cultural Change in the Peruvian Rainforest. Journal of Tropical Medicine and Hygiene, 1992; 95(2):104-13

28. Monárrez-Espino J, Pérez-Espejo $\mathrm{CR}$, Vázquez-Mendoza G, et al. Intervention to Prevent Intestinal Parasitic Reinfections among Tarahumara Indigenous Schoolchildren in Northern Mexico. Revista Panamericana de Salud Pública,2011; 30, 196-203.

29. Muslim A, Mohd Sofian S, Shaari SA, et al. Prevalence, Intensity and Associated Risk Factors of Soil Transmitted Helminth Infections: A Comparison between Negritos (indigenous) in Inland Jungle and those in Resettlement at Town Peripheries. PLOS Neglected Tropical Diseases 2019; 22;13(4):e0007331

30. Park MJ, Laksono B, Clements A, et al. Worm-free children: an Integrated Approach to Reduction Of SoilTransmitted Helminth Infections in Central Java. Reviews on Environmental Health 2016; 31(1):111-113

31. Mohd-Shaharuddin N, Lim YAL, Hassan NA, et al. Soil-transmitted helminthiasis among indigenous communities in Malaysia: Is this the endless malady with no solution. Tropical Biomedicine, 2018; 35(1), pp.168-180.

32. Ngui R, Aziz S, Chua KH, et al. Patterns and risk factors of soil-transmitted Helminthiasis among Orang Asli subgroups in Peninsular Malaysia. The American Journal of Tropical Medicine and Hygiene, 2015; 93(2), pp.361-370

33. Freeman $M$, Chard A, Nikolay B, et al. Associations between School-and Household-Level Water, Sanitation And Hygiene Conditions And Soil-Transmitted Helminth Infection among Kenyan School Children. Parasites \& vectors 2015; 8: 412.

34. Anuar TS, Al-Mekhlafi HM, Ghani MK, et al. Giardiasis among Different Tribes of Orang Asli in Malaysia: Highlighting the Presence of Other Family Members Infected with Giardia Intestinalis as a Main Risk Factor. International Journal for Parasitology, 2012; 1;42(9):871-80.35.

35. Khor G \& Zalilah M. The Ecology of Health and Nutrition of Orang Asli (Indigenous People) Women and Children in Peninsular Malaysia. Tribes and Tribals, 2008; 2, 6677.

36. Senay H, MacPherson D. Parasitology: Diagnostic Yield of Stool Examination. Canadian Medical Association Journal. 1989; 140:1329-1331

37. Atef H, Samia M, Ibrahim A, et al. Intestinal Parasite Infections and Accuracy of Direct Thin and Thick Smear, Formol- Ether Sedimentation, Centrifugal Flotation, and Mini FLOTAC Techniques Among Patients with Gastrointestinal Tract Disorders from the Greater Ciro Region, Egypt. The American Journal of Tropical Medicine and Hygiene, 2017; 96(3):589-594.

38. Oguoma V, Ekwunife C. The Need for a Better Method: Comparison of Direct Smear and Formol-Ether Concentration Techniques in Diagnosing Intestinal Parasites. International Journal of Tropical Medicine, 2006; 3:1-6. 